\title{
A "POLÍ́CIA" E AS FUNÇÕES DO ESTADO - NOTAS SOBRE A "POLÍ́CIA" DO ANTIGO REGIME
}

\author{
POLICE AND STATE FUNCTIONS UNDER THE ANCIENT RÉGIME
}

\author{
Airton Cerqueira Leite Seelaender*
}

\begin{abstract}
RESUMO: A natureza contingente e mutável da linguagem jurídica revela-se claramente nas alterações de significado que afetaram a palavra "polícia" desde o início da Idade Moderna. O conceito identificavase, então, sobretudo com a defesa da moral cristã e da ordem estamental contra a "desordem" e as "novidades" decorrentes das transformações da sociedade. Refletindo e embasando a posterior refuncionalização da Coroa, o conceito alargou-se, porém, enormemente na época do reformismo absolutista. No século XVIII, ele já englobava toda a gestão interna do Estado e todos os esforços deste- inclusive através de específicas "leis de polícia" - para ampliar a riqueza e o número dos súditos, supostas bases do poderio estatal. Nesse contexto, evidenciando o caráter cada vez mais instrumental do próprio direito, a legislação de polícia tornou-se uma ferramenta para transformar a realidade, dirigindo e disciplinando os súditos. Expressando pretensões absolutistas, a ideia de "polícia" se converteria, no século XIX, em um objeto incômodo para o pensamento jurídico liberal.
\end{abstract}

PALAVRAS-CHAVE: Polícia. Governo da "Casa" e Reino. Absolutismo. "Polizeiwissenschaft". Administração Pública. Liberalismo e "polícia".

ABSTRACT: The changes in meaning undergone by the word "police" since the beginning of the Modern Era clearly reflect the changeable nature of legal language. At that time the concept was associated mainly with the protection of Christian morality and social order against "disorder" and innovations brought in by social transformations. The concept was though greatly broadened in the times of absolutist reformism, mirroring and supporting the Crown subsequent new functions. In the eighteenth century the term already included in its meaning the whole internal management of the State, as well as all its measures - including specific "police laws" - aiming at an increase in wealth and in the number of subjects, which were supposedly the very basis of State power. In this context, "police law" became a tool to transform reality by means of directing and disciplining subjects, showing the increasing instrumental character of law itself. The idea of "police" was so closely connected to Absolutism that it became an embarrassing topic for the liberal legal thought in the 19th century

KEYWORDS: Police. "House" and Kingdom. Absolutism. "Polizeiwissenschaft". Public Administration. Liberalism and "police".

* Doutor pela Universidade J.W. Goethe/Frankfurt. Professor de Direito Constitucional e História do Direito na UFSC. 
1. Usualmente relacionado, no Brasil de hoje, às instituições de segurança pública ou à ideia uma atividade estatal destinada a assegurar as condições mínimas de coexistência de direitos de particulares, o termo "polícia" já comportou significados mais amplos. As alterações de seu sentido, ao longo da história, espelharam e legitimaram importantes mudanças de concepção quanto à função dos governantes e quanto à estruturação do Estado.

Supõe-se que, surgindo como variante dos termos clássicos "política" e "politeia", a palavra "polícia" teria sido cunhada por letrados medievais, provavelmente no século $\mathrm{XIV}^{1}$. Incorporando-se ao jargão da chancelaria do Duque de Borgonha, dali se teria difundido para outras cortes européias.

Em seu significado originário, "polícia" remeteria às idéias de "governo" e "bom governo" dentro de um reino ou cidade - e daí às de "boa ordem", "ordem" e mesmo "civilidade" e "urbanidade" ${ }^{2}$. Note-se que, na tradição aristotélica, correspondia à "política" cuidar da pólis, assim como cabia à "economia" tratar da gestão da casa e à ética dirigir o indivíduo. Transpondo-se isso para as condições das monarquias europeias da Idade Moderna, caberia à "política" ou "polícia" cuidar do governo do reino.

No contexto da época, a linha divisória entre a "polícia" e a "economia" soava, contudo, um tanto artificial: visto o rei como figura paterna e compreendida a "economia" a partir do modelo da casa senhorial ${ }^{3}$, não era difícil conceber o rei, supremo senhor, como o "pai" e governante da "grande casa do Reino"4. Assim sendo, "polícia" e "economia" eram conceitos tendentes a se misturar ${ }^{5}$. Assim como o "pai" podia, no "governo econômico" que exercia, comandar, educar, disciplinar e punir criados e familiares, assim também podia fazê-lo o pai-rei com seus súditos - "filhos", na grande

1 cf- além de KNEMEYER, F.-L. (1978)- MAIER, H. (1980), p.97.

2 Um livro português de 1619 elencava entre os "pecados contra a polícia" o hábito de "borrifar as palavras" com saliva. Outro, publicado em 1710, ensinava "polícia e urbanidade cristã" desaconselhando, e.g., a limpeza de dentes com toalhas de mesa (cf. ANÔNIMO (1710), v.1, p.377, e LOBO, F. R. (1937), p.63).

Esse emprego do termo "polícia" no sentido de "urbanidade" também ocorreu em outros países (cf. MAIER, H. (1980), p.102 e ss.; e SCHULZE, R. (1982), p.15).

3 Pelo menos este teria sido o modelo, no ver de Otto Brunner- o mais influente estudioso do tema (cf., e.g., SIMON, T. (2004), p.417).

4 Verificável na Alemanha sobretudo no final do século XVII, tal paralelo seria, segundo J. Brückner, decorrência de um processo de "paternalização da imagem do Príncipe". Thomas Simon, por sua vez, crê que ele espelharia mais a difusão da idéia de que o governante deveria, à maneira do "pai de família" ("Hausvater"), passar a atuar como gestor no campo econômico (sobre o tema cf.SIMON, T.(2004), p.431ss, esp.p.433; STOLLEIS, M. (1988), p.341-2, e FRIGO, D. (1991), p.47ss. Relativizando, por outro lado, tal paralelo no período anterior, SIMON, T. (2004), 417ss. Sobre a equiparação do reino à casa em Portugal, cf.-além dos estudos de A. HespanhaSEELAENDER, A.C.L. (2003a), p.143ss, 175, 212-3, 217, 223-4, etc.).

5 Com seu "Traité de l'oeconomie politique" já indicava Montchrétien em 1611 uma tendência à superação da dicotomia aristotélica (cf.MAIER, H. (1980), p.171). 
casa do reino. Do mesmo modo que um "paterfamilias" ou "Hausvater" podia expulsar de sua propriedade um visitante indesejável, podia o rei expulsar da grande casa do reino comerciantes estrangeiros, ciganos, ordens religiosas e companhias mercantis de outros estados ${ }^{6}$.

Essa equiparação entre governo do reino ("polícia") e governo da casa (“economia") permitia estender ao primeiro o que se via como atributo do segundo: um amplíssimo direito de regular a convivência e de reprimir maus comportamentos, para que se preservassem a paz doméstica e a "boa ordem". Ora, tal extensão facilitava, na vasta casa do reino, o fortalecimento do papel do rei, tradicionalmente limitado pela ordem jurídica herdada do passado. Para proteger ou restaurar a "boa ordem" no reino parecia aceitável, circunstancialmente, até que se contornassem prescrições do direito feudal e do direito costumeiro. Ou que se relativizassem ou ignorassem os privilégios de indivíduos, corporações, municipalidades e estamentos ${ }^{7}$.

Dentro desse quadro, a concepção de uma "polícia do reino" servia para legitimar - a partir de pontos de apoio externos ao que então se via como o campo "jurídico" - a desconsideração de barreiras jurídicas ao poder monárquico. Não por acaso, a expansão do Absolutismo foi acompanhada - e sinalizada - pela criação de cátedras de "polícia” em universidades (1727 na Prússia, 1752 na Áustria) e pela multiplicação de agentes e órgãos "de polícia" (como os intendentes) ${ }^{\text {. }}$.

Típica expressão de um maduro Absolutismo Reformador foi também o vicejar de uma literatura específica sobre a "polícia”. Se a França de Luís XIV produziu o primeiro grande "clássico" do ramo - o "Traité de la police" (1705) de N. Delamare -, seria, porém, nos territórios de língua alemã regidos por príncipes absolutos que surgiriam, nas pessoas de Justi $(+1770)$ e Sonnenfels $(+1817)$, os mais destacados teóricos da "Ciência da Polícia" ("Polizeiwissenschaft"). Herdeira da tradição local de reflexão sobre os meios de gerir o tesouro de um Príncipe (“Cameralística”), tal ciência ia muito além disso, veiculando um amplo programa de racionalização e disciplinamento da vida econômica e social.

Vista por vezes como uma variante austro-alemã do Mercantilismo, própria de estados sem colônias, a "Polizeiwissenschaft" encarava, como este, a economia como uma raiz e função do poder estatal9 . Olhando com mais atenção para dentro do Estado,

6 Para exemplos em Portugal, cf.SEELAENDER, A.C.L. (2003a), p.144.

7 A difusão das doutrinas da "razão de estado" também viria a contribuir, com o tempo, para tal relativização (para uma análise recente do tema da "razão de estado" e da bibliografia correspondente, cf.BERCOVICI, G. (2008), p.72ss).

8 Sobre o processo de diferenciação da "polícia" nas esferas científica e administrativa, cf. STOLLEIS, M. (1988), p.366ss. e MAIER, H. (1980), p.177ss.

9 Para uma discussão do tema, cf.SIMON, T. (2004), p.452-3. 
apresentava, porém, tendências próprias, preocupando-se em remodelar o aparato administrativo e em ampliar substancialmente os mecanismos de controle social e de instrumentalização dos governados pelos governantes ${ }^{10}$.

Considerando-se a relativa prosperidade do reinado de D.João V (1706-1750) e a clara vinculação entre as necessidades financeiras do Absolutismo e o desenvolvimento das técnicas "policiais" de estímulo à atividade econômica interna, não seria difícil de explicar o relativo atraso com que surgiram, em Portugal, os primeiros espaços institucionais para discussão e estudo dessa temática ${ }^{11}$. Seria apenas no regime pombalino - diante da crise financeira e da instabilidade política, econômica e social da época - que se criaria a Intendência Geral da Polícia (1760) e se tentaria, mediante a reforma da Universidade de Coimbra (1772), dar aos futuros servidores da Coroa alguns conhecimentos básicos sobre a polícia real ${ }^{12}$. De qualquer modo, parecem ter inexistido - ao menos até a criação da Real Academia das Ciências de Lisboa (1779/1780) no reinado de D.Maria I - instituições permanentes destinadas à produção e transmissão de técnicas de fomento econômico e de estímulo ao crescimento populacional.

2. Encarada inicialmente como um campo separado daquele do direito, a "polícia" podia e devia ser, porém, objeto de normatização. Com a Coroa desejando controlar cada vez mais a vida social, começaram a surgir inúmeras "leis de polícia" ("Polizeigesetze"), de início muito ligadas às idéias de preservação ou restauração da ordem. Na era barroca, o choque provocado na sociedade pelas novas tendências econômicas e comportamentais fez com que o poder político optasse, muitas vezes, por combater as "novidades", em nome da "conservação" do Estado e da ordem social tradicional vista como seu principal esteio ${ }^{13}$.

Cabia à "polícia", nesse contexto, restaurar a "boa ordem", combatendo práticas e vícios contrários aos valores tradicionais de roupagem cristã (jogo, bebida, prostituição, bigamia, desonestidade no comércio, sedução de freiras), bem como chocantes condutas novidadeiras (como o nomadismo dos ciganos e de camponeses desenraizados, ou a imitação, por burgueses ricos, do modo de vida aristocrático) ${ }^{14}$. Especial ênfase era dada, aqui, à proteção das barreiras interestamentais e intraestamentais: regulava-se detalhadamente não só a ordem de precedências em todas as ocasiões imagináveis, mas

${ }^{10}$ cf.MAIER, H. (1980), p.181 e 186- com imprecisões apontadas em SIMON, T. (2004), p.452-3.

${ }^{11}$ Sobre esta e outras razões do "atraso relativo" em questão, cf.SEELAENDER, A.C.L. (2003a), p.110ss.

${ }^{12}$ Sobre o estudo das "leis de polícia" dentro da nova matéria "Direito Pátrio"- e sobre os enormes óbices a sua concretização- cf.SEELAENDER, A.C.L. (2003a), p.119-121.

${ }^{13}$ Destacando-se na vasta bibliografia sobre o tema, MARAVALL, J.A (1997).

${ }^{14}$ Para uma análise da restauração da "boa ordem" como razão de ser da "polícia" no início da Idade Moderna, cf.MAIER, H. (1980), p.100ss; SIMON, T. (2004), p.111ss, 218ss e 563; etc. 
também tudo o que pudesse indicar a posição social de alguém (roupas, chapéus, carruagens, caixões, formas de tratamento $)^{15}$. Daí o combate incessante ao luxo - que, além de perigoso para as almas e para o patrimônio dos súditos, podia ocultar escandalosamente as diferenças estamentais ${ }^{16}$.

No meio urbano, a palavra "polícia" logo foi relacionada à gestão interna da cidade nos aspectos que mais afetavam seu dia a dia. Construção e conservação de ruas, abastecimento de água, limpeza urbana, prevenção de incêndios, controle de pesos e medidas no comércio - tudo isso se inseria no âmbito da "polícia" urbana. Esta já revelava, aliás, embrionariamente, aspectos que viriam a marcar, depois, a concepção de "polícia" do Absolutismo Reformador: tendência à desconsideração do privilégio "irrazoável", preocupação com a vida econômica, certo esvaziamento dos mecanismos judiciais de controle da atuação pública.

Foi, porém, em espaços mais amplos - reinos e principados - que se impulsionaram as maiores transformações da idéia de "polícia". À medida que se acirravam as disputas territoriais no continente, cresciam de forma acelerada os exércitos, as frotas e as despesas para sua manutenção ${ }^{17}$. Com isso, vários governos vieram a preocupar-se intensamente com o crescimento populacional e com o aumento da arrecadação, passando a desestimular o celibato, promover a imigração, impor padrões de higiene, estimular as manufaturas, instituir companhias coloniais, combater o ócio, dar maior segurança aos comerciantes, facilitar a circulação de bens etc. ${ }^{18} \mathrm{O}$ termo "polícia" foi então adotado para designar o imenso leque de atividades e opções políticas assumidas pela Coroa, na tentativa desta de multiplicar e enriquecer seus súditos e, assim, dar ao poderio estatal bases sólidas ${ }^{19}$.

Em uma das obras mais influentes sobre o tema, J.H.G. von Justi ${ }^{20}$ definia a "polícia" como o conjunto de "todas as medidas em assuntos internos", por meio das

${ }^{15}$ Para uma análise da legislação lusitana e seus objetivos de diferenciação estamental, cf.SEELAENDER, A.C.L. (2003a), p.48-9.

${ }^{16}$ Sobre a "legibilidade da ordem estamental" como meta, cf.SIMON, T. (2004), p.117ss e a bibliografia ali indicada. Já sob o prisma econômico, cumpre advertir, ainda, que o combate ao luxo também tinha usualmente o objetivo de reduzir importações e assim impedir a "fuga da moeda" para outros estados (cf., e.g., as leis portuguesas elencadas em SEELAENDER, A.C.L. (2003a), p.48, n.14).

${ }^{17}$ Sobre a aceleração dos conflitos externos como impulso fundamental cf.MAIER, H.(1980), p.159; SIMON, T. (92004), p.276, 564, etc., e os dados e fontes referidos em SEELAENDER, A.C.L. (2007), p.263-4.

${ }^{18}$ Indicando essa nova orientação, há, e.g., uma enorme variedade de assuntos nas leis portuguesas pós1750 que trazem a palavra "polícia" (cf.SEELAENDER, A.C.L. (2003b), p.93).

${ }^{19}$ Como destaca Simon, se os custos financeiros mal afetavam a "polícia" conservadora/restauradora do início da Idade Moderna, a nova "polícia" giraria em torno do dinheiro, abarcando todas as áreas e matérias que pudessem ter impacto no aumento da riqueza estatal (v.SIMON, T.(2004), p.564ss).

${ }^{20}$ JUSTI, J. H. G. v.(1969), p.4. Talvez "felicidade da "república"” (no antigo sentido deste termo) traduzisse aqui melhor "Glückseligkeit des gemeinen Wesens". 
quais se pudesse "de forma mais duradoura fundamentar e aumentar o patrimônio geral do Estado, utilizar melhor as forças do Estado e em especial fomentar a felicidade da comunidade". Mesmo tomada "em sentido estrito", ela englobaria tudo o que escorasse "a boa constituição da vida civil", da manutenção da ordem ao fomento da riqueza geral ${ }^{21}$. Na busca da "felicidade" - aqui identificada com a prosperidade dos súditos ensejadora do poderio do Estado ${ }^{22}$ - a "polícia" deveria se ocupar de uma infinidade de assuntos, do combate à mendicância às práticas sexuais dos súditos, da defesa das manufaturas à criação de abelhas.

Deixando de ser uma atividade marginal do poder real ou citadino, a "polícia" se convertia, agora, no conceito-síntese da gestão interna do Estado. Ela não veiculava, mais, só uma tentativa de restaurar uma "boa ordem" supostamente preexistente comprometia-se agora com a mudança. Tornava-se um meio pelo qual o Estado Absolutista, dirigindo, moldando e instrumentalizando seus súditos, multiplicava estes e suas riquezas, expandindo as fontes últimas do poderio político-militar da Coroa.

Particularmente perceptível na Prússia e na Áustria, tal fenômeno também ocorreu em Portugal. Na segunda metade do século XVIII, acentuou-se ali o uso da "lei de polícia" como ferramenta para a modificação da realidade. Esta não visava mais à simples restauração de uma "boa ordem" ideal, vista como "quebrada". Visava agora, sim, a uma transformação do existente, para permitir o crescimento, a acumulação e a maximização de tudo o que fortalecia o Estado. Tinha a lei de promover efetivamente o aumento populacional, o enriquecimento dos súditos, o progresso cultural, a colonização de regiões abandonadas, a maior integração de indígenas e "cristãos-novos" na sociedade, o surgimento de novas companhias e manufaturas, o disciplinar das camadas populares e o aprimoramento das condições de limpeza e segurança da capital.

Que as novas tarefas da "policia" exigiam um Estado bastante ativo, isso era evidente. Tal atividade, no entanto, não poderia gerar resultados, se sofresse bloqueios a todo momento, por parte de orgãos e instituições dotados de visão tradicionalista. Não por acaso, o vicejar da nova "polícia" costumava ser precedido ou acompanhado pela supressão de assembleias estamentais e pelo crescimento do controle real sobre o clero. E ocorria, geralmente, por meio de uma deliberada contenção da influência dos tribunais "de Justiça” e dos juízes de formação jurídica tradicional. Era comum que, ao implementar medidas de polícia, o Governo criasse "tribunais de polícia" e "intendentes de polícia" dotados de competência privativa para julgar, no lugar da Justiça ordinária, os conflitos daí decorrentes.

${ }^{21}$ Idem, ibidem.

${ }^{22}$ Essa "felicidade" de Justi- como frisamos em trabalho anterior (SEELAENDER, A.C.L (1995))- não tornava o governado o fim da atividade estatal: longe disso, confundia-se com um ambiente de prosperidade material dos súditos, que nada mais era, em última análise, do que uma outra face do "poderio interno do Estado" (para uma precisa demonstração disso, cf. também SIMON, T. (2004), p.510ss). 
A tentativa de contornar os órgãos da Justiça ordinária fazia também sentido, em razão das diferentes lógicas da nova "polícia" e do direito tradicional. Se este se devia preocupar com justiça, conservação de padrões procedimentais do "iudicium" e preservação de direitos e privilégios preexistentes ("iura quaesita"), aquela não tratava estes como intocáveis e dava muito mais importância à utilidade e a eficiência ${ }^{23}$. Não por acaso, adotou-se, nos órgãos de polícia encarregados do controle social e da gestão econômica, um processo distinto do ordinário e bem mais célere do que este ${ }^{24}$. Não raro ali se dificultava a defesa e mesmo se suprimiam os recursos, alegadamente em nome da efetividade e do bem comum ${ }^{25}$.

Onde o absolutismo gerou uma evolução mais acentuada da máquina estatal como na França, Prússia e Áustria - não faltaram experiências e situações muito próximas dessa nossa simplificadora descrição. Vistas como modelos de êxito, tais monarquias inspirariam reformas, no século XVIII, em Portugal, na Espanha e em outros estados europeus. Leis, órgãos e concepções da "polícia" absolutista passariam, assim, de um país a outro - tendo sua recepção facilitada onde o Estado concentrava a iniciativa econômica, organizando em sua órbita uma burguesia pequena demais para sair de sua sombra.

3. As bases da "polícia" absolutista começaram a ser corroídas na fase final do Antigo Regime, em sociedades mais dinâmicas - como a francesa - em que crescia a oposição às ingerências da Coroa na vida social, sobretudo na esfera econômica. Onde a burguesia se fortalecia a ponto de não precisar mais orbitar em torno das iniciativas do Estado, ampliava-se a resistência às companhias privilegiadas, às manufaturas monopolistas, às interferências governamentais nos negócios particulares e aos tributos necessários para manter a máquina administrativa em expansão. Cada vez mais desfavorável à "polícia” absolutista, tal quadro se agravava com a difusão de idéias que a punham em xeque - como a limitação do espaço de atuação "legítima" do poder estatal (de Locke a Humboldt) - a crença na racionalidade intrínseca e na capacidade

23 Sobre a relação "Polizei”/"iura quaesita", cf.PREU, P. (1983), p.59-77, além das ponderações de MATSUMOTO, N. (1999), p.49-50; e SIMON, T. (2004), p.358ss. Para uma síntese das tensões entre a "polícia" e o jurista português tradicional, SEELAENDER, A.C.L. (2003a), p.115ss e as obras ali indicadas. Sobre a lógica do aparelho judiciário tradicional, uma das melhores descrições encontra-se em HESPANHA, A.M. (1994).

${ }^{24}$ Com base em fontes portuguesas e discordando da visão de T. Simon, temos sustentado que não seria exagero falar em um "processo de polícia", com características próprias (irrecorribilidade ou quase-irrecorribilidade das decisões, substancial limitação de provas para a defesa, redução de prazos em nome da maximização da efetividade, acentuada ampliação dos poderes do magistrado "policial”, etc.).

${ }^{25}$ Em 1661 uma "Polizeiordnung" da Saxônia já frisava tal orientação. Nas décadas seguintes, o afastamento do processo ordinário também seria previsto em outros diplomas, na Saxônia, na Prússia e na Baviera (cf.PREU, P. (1983), p.78. Sobre o tema- aprofundando o exame da polêmica sobre a (ir)recorribilidade das decisões em matéria de polícia- cf.SIMON, T. (2004), p.355ss). 
autorreguladora do mercado (fisiocratas franceses, Adam Smith) e a demolição das bases filosóficas do Estado Eudemonístico (Kant) ${ }^{26}$.

Na França, a Revolução acelerou uma revisão radical do papel do Estado. Verificaram-se ali claros esforços no sentido de destruir as bases ideológicas da "polícia" do Antigo Regime - como a concepção do monarca como um "pai" apto a tudo regular na "grande casa do Estado".

É bem verdade que o fomentismo econômico não foi, na França, de todo eliminado - e que se verificou mesmo uma intensificação da atividade estatal em campos já vistos, antes, como tipicamente "policiais" (e.g., a educação e a segurança pública). E é fato - como mostrou Tocqueville ${ }^{27}$ - que, no campo administrativo, não faltaram linhas de continuidade entre os regimes pré-1789 e pós-1789, tendo os revolucionários de certa forma implementado o projeto centralizador e racionalizador do Absolutismo. De qualquer modo, muito associado - como os "Intendentes de Polícia" - ao regime anterior, o próprio termo "polícia" passou a ser substituído pela expressão "administração pública", politicamente menos carregada ${ }^{28}$.

Muito embora as áreas de ação da "Administração Pública" e os assuntos dos novos tratados de "Ciência da Administração" parecessem espelhar muito do conteúdo da "polícia" do Antigo Regime ${ }^{29}$, teria ocorrido, na França pós-1789, um certo reforço das exigências de "legalidade" na atuação administrativa, lastreado em providências legislativas e em mecanismos administrativos de controle ${ }^{30}$. Se é bem verdade que os mecanismos de proteção do administrado eram ainda incipientes, nem por isso deixou de se verificar, ali, uma mudança essencial, no que tange às concepções básicas sobre as condições de legitimidade da ação da máquina pública ${ }^{31}$.

${ }^{26}$ cf- além de MATSUMOTO, N. (1999) - BOBBIO, N. (1984), p.136ss; STOLLEIS, M. (1988), p.384-5; MAIER, H. (1980), p.195ss e 205-6, e SCHIERA, P (1986), p.412.

27 Segundo tal autor, a Revolução teria emergido do Antigo Regime, dando continuidade à política de centralização deste último (v.TOCQUEVILLE, A. de (1986), p.947ss, 973ss, 979ss, 985ss, 988-990, 1074, etc.)

${ }^{28}$ Para uma análise da tabuização do termo "policia" no liberalismo português, cf.SEELAENDER, A.C.L. (2003), p.75-6 e 110, bem como as fontes ali indicadas.

${ }^{29}$ Vendo sinais de certa continuidade mesmo na literatura de direito administrativo, BURDEAU, F. (1995), p.111-3. A existência de linhas de continuidade talvez explique também, em parte, porque livros que tratavam da "polícia" e do "direito de polícia" do Antigo Regime podiam seguir sendo usados, em plena era liberal, em faculdades brasileiras e portuguesas (cf SEELAENDER, A.C.L. (2003a), p.109-110). Na Áustria, a "Ciência da Polícia" se manteria até a década de 1860 matéria obrigatória para os servidores públicos (cf.MAIER, H. (1980), p.193).

${ }^{30}$ Sobre o assunto- e fazendo amplas ressalvas-BURDEAU, F. (1995), p.42ss, 54ss e 59. Advirta-se, em todo caso, que a exclusão do controle judicial, nessa esfera, não visava precipuamente a esvaziar os direitos dos cidadãos afetados pela Administração, mas sim a preservar a Separação de Poderes.

${ }^{31}$ Embora nas fases de crise econômica, instabilidade política ou radicalização revolucionária os "escrúpulos legalistas" não tenham imperado (BURDEAU, F. (1995), p.58-9), o fato é que a Revolução veiculou e difundiu o culto da lei e a crença de que só esta poderia fundamentar restrições a liberdades (cf., e.g., o art.4. da "Déclaration des droits" de 1789, que seria incorporada à Constituição de 1791). 
Na Alemanha pré-1848, longe esteve de ser frequente, na literatura especializada sobre "polícia", a defesa de uma acentuada limitação do âmbito material de atividades estatais $^{32}$. Em diversos estados alemães, o papel central da burocracia e do Estado na organização da vida social e econômica persistiu por muito tempo após a crise do Antigo Regime e as invasões napoleônicas.

Mais representativa talvez fosse, dentro desse quadro, a postura do juspublicista Robert von Mohl (+1875). Tal autor tentou conciliar a segurança do Estado de Direito com uma ampla atuação estatal - tentativa espelhada em obras como "Die PolizeiWissenschaft nach den Grundsätzen des Rechtsstaates" (1832). Ainda abrangendo inúmeras matérias de sua fase absolutista, a "polícia" seguia sendo vista, aqui, como um vasto e imprescindível campo do agir estatal. Mesmo porque - perguntava-se Mohl "quem gostaria e poderia viver em um Estado que só exercesse Justiça", deixando de lado as atividades de polícia ${ }^{33}$ ?

O Estado de Direito tinha de ordenar o exercício do poder e proteger os indivíduos contra violações de seus direitos, mas não se podia deter nisso. Devia, também, diante da "insuficiência das forças individuais", agir subsidiariamente, utilizando "todo o poder que lhe era confiado" para atingir as "finalidades vitais racionais" do "povo" ${ }_{34}$. Sem impor concepções estatais de "felicidade" a ninguém, devia facilitar, para os governados em geral, a busca da felicidade e do aperfeiçoamento individuais ${ }^{35}$. Dentro desse quadro, competia à "polícia" sobretudo aplainar o caminho para o progresso dos indivíduos e suas associações, eliminando toda sorte de obstáculo fático ${ }^{36}$.

Se essas reflexões de Mohl tendem a nos soar como um estranho eco de épocas distantes, por outro lado não parece hoje menos antiquada a proposta de alguns liberais do século XIX, de simplesmente eliminar do mundo jurídico toda idéia de "polícia", como filha do Absolutismo. Na verdade, a sobrevivência de um termo politicamente tão incômodo é um claro indício de sua maleabilidade e utilidade, tanto no século XIX quanto no período posterior. Temos aqui um fato eloquente - que só uma doutrina sonâmbula poderia ignorar.

32 cf.STOLLEIS, M. (1988), p.385, e MATSUMOTO, N. (1999), p.225- que menciona como principal exceção os adeptos radicais de Kant- mas não o próprio Kant- na década de 1790.

\footnotetext{
${ }^{33}$ MOHL, R. v. (2005), p.5.

${ }^{34}$ Idem, ibidem.

35 cf.MAIER, H. (1980), p.220.

${ }^{36}$ MOHL, R. v. (2005), p.6-7.
} 


\section{BIBLIOGRAFIA}

ABOYM, Diogo Guerreiro Camacho de (1759). Escola moral, política, christãa e jurídica. 3.ed., Lisboa.

BAENA DEL ALCÁZAR, Mariano (1968). Los estudios sobre administración en la España del siglo XVIII. Madrid, Instituto de Estudios Políticos.

BERCOVICI, Gilberto (2008). Soberania e constituição. S.Paulo, Quartier Latin.

BIRTSCH, Günter (1987). “Der Idealtyp des aufgeklärten Herrschers”. Aufklärung 2,1 (1987): p.9-47.

BOBBIO, Norberto (1984). Direito e Estado no pensamento de Emanuel Kant. Brasília, UNB.

BRAUNEDER, W. (1995). "Sonnenfels, Joseph von”. in: STOLLEIS, M. (org.)- Juristen- ein biographisches Lexikon. München, C.H. Beck, p.577-9.

CHAUNU, Pierre (1982). La Civilisation de l'Europe des Lumières. Paris, Flammarion.

COLLINS, James B. (1999). The State in Early Modern France. Cambridge/N.York, Cambridge University Press.

COMPÊNDIO HISTÓRICO DO ESTADO DA UNIVERSIDADE DE COIMBRA (1972). Coimbra, Universidade de Coimbra (reimpressão da ed. Lisboa 1771).

DEDUCÇÃO CHRONOLOGICA, E ANALYTICA (1768). Lisboa, Officina de Miguel Manescal da Costa. DIXON, Simon (1999). The Modernisation of Rússia 1676-1825. Cambridge, Cambridge University Press. DURAND, Bernard (1996). "La Notion de Police en France du XVIe. au XVIIIe. siècle". In: STOLLEIS, M. (Org.). Policey im Europa der Frühen Neuzeit. Frankfurt/M., V. Klostermann, p.163211.

EBIHARA, Akio (1985). "Justis Staatslehre und Wolffs Naturrechtslehre". Zeitschrift der SavignyStiftung für Rechtsgeschichte (G.Abt.) 102 (1985), p.239-246.

ELLIOTT, J. H. (1998). "Introspección colectiva y decadencia en España a principios del siglo XVII”. In: ELLIOTT, J.H. (Org.). Poder y sociedad en la España de los Austrias. Barcelona, Crítica, p.198-223.

ELLIOTT, J. H. (1989). Europe Divided 1559-1598. London, Fontana Press, 1989.

ELLIOTT, J. H. (1998). Imperial Spain. London, Penguin.

ELLUL, Jacques (1991). Histoire des institutions. 11 a.ed., Paris, PUF.

ESCUDERO, José Antonio (1995). Curso de Historia del Derecho. Madrid.

FRANÇA, Eduardo D’Oliveira (1997). Portugal na época da Restauração. S.Paulo, Hucitec.

FRANÇA, José-Augusto (1984). "Burguesia pombalina, nobreza mariana, fidalguia liberal". in:SANTOS, M.H.C. dos (Org.). Pombal revisitado. Lisboa, Estampa, v.1, p.19-33.

FRENSDORFF, Ferdinand (1970). Über das Leben und die Schriften des National-Ökonomen J.H.G. von Justi. Glashütten, D. Auvermann.

FRIEDRICH DER GROSSE (1987). Das politische Testament von 1752. Stuttgart, Reclam.

FRIGO, Daniela (1991). “Disciplina rei familiariae”. Penélope 6 (1991), p.47-62.

GARCÍA-GALLO, Alfonso (1984). Manual de historia del derecho español. Madrid, v.2. 
GAY, Peter (1977). The Enlightenment. N.York/ London, W.W. Norton.

GILISSEN, John (1988). Introdução histórica ao direito. Lisboa, C.Gulbenkian.

GOUBERT, Pierre (1996). Le Siècle de Louis XIV. (Paris), Éditions de Fallois.

GUSMÃO, Alexandre de (1981). Cartas. Lisboa, Imprensa Nacional/Casa da Moeda.

HECKSCHER, Eli F. (1983). La época mercantilista. México, Fondo de Cultura Econômica, 1983.

HESPANHA, António M. (1978). A história do direito na história social. Lisboa, Livros Horizonte.

HESPANHA, António M. (1982). História das instituições. Coimbra, Almedina.

HESPANHA, António M. (1984). "Para uma teoria da história institucional do Antigo Regime". in:HESPANHA, A.M. (Org.). Poder e instituições na Europa do Antigo Regime. Lisboa, Gulbenkian.

HESPANHA, António M. (1988). “Nota do tradutor”. in:GILISSEN, John- Introdução histórica ao direito. Lisboa, Gulbenkian, p.648-651.

HESPANHA, António M. (1992). Poder e instituições no Antigo Regime. Guia de estudos. Lisboa, Cosmos.

HESPANHA, António M. (1994). Às vésperas do Leviathan. Coimbra, Almedina.

HESPANHA, António M. (1998). Panorama histórico da cultura jurídica européia. $2^{\text {a }}$.ed., (Lisboa), Europa-América.

HINRICHS, Ernst (1986b). "Merkantilismus in Europa". in:HINRICHS, Ernst (org.)-Absolutismus. Frankfurt a.M., Suhrkamp, p.344-361.

HINRICHS, Ernst (1989). Ancien Régime und Revolution. Frankfurt a.M., Suhrkamp.

HINZE, Otto (1981). Beamtentum und Bürokratie. Göttingen, Vandenhoeck \& Ruprecht.

HOF, Hagen (1989). "Josef von Sonnenfels”. In:KLEINHEYER, G./SCHRÖDER, J.(Org.).

Deutsche Juristen aus fünf Jahrhunderten. 3.ed., Heidelberg, C.F.Müller, p.260-264.

JUSTI, Johann Heinrich Gottlob von (1965). Die Grundfeste zu der Macht und Glückseligkeit der Staaten. Aalen, Scientia Verlag (reimpressão da ed. Königsberg/Leipzig 1761).

JUSTI, Johann Heinrich Gottlob von (1969). Grundsätze der Policeywissenschaft. Frankfurt a.M., Sauer \& Auvermann (reimpressão da 3.ed. Göttingen, 1782).

JUSTI, Johann Heinrich Gottlob von (1969b). Natur und Wesen der Staaten. Aalen, Scientia Verlag, (reimpressão da 2a.ed. Mitau, 1771).

JUSTI, Johann Heinrich Gottlob von (1978). Vergleichungen der europäischen mit den asiatischen und andern vermeintlich barbarischen Regierungen. s.l., Scriptor Verlag (reimpressão da ed. Berlin/ Stettin/Leipzig, 1762).

KATHARINA II (1970). Instruction für die zu Verfertigung des Entwurfs zu einem neuen Gesetzbuche verordnete Commission. Frankfurt/M, F. Keip (reimpressão da ed. Riga/Mietau, 1768).

KLUETING, Harm (1986). Die Lehre von der Macht der Staaten. Berlin, Duncker \& Humblot.

KNEMEYER, Franz-Ludwig (1978). "Polizei". In: BRUNNER, O./CONZE, W./KOSELLECK, R. (org.)- Geschichtliche Grundbegriffe. Stttgart, Klett-Cota, v.4, p.875-897.

KOSELLECK, Reinhart (1992). "Begriffsgeschichte und Sozialgeschichte". Vergangene Zukunft. 2.ed., Frankfurt/M., Suhrkamp, p.107-129. 
KUNISCH, Johannes (1986). Absolutismus. Göttingen, Vandenhoeck \& Ruprecht.

LADURIE, Emmanuel Le Roy (1992). "Présentation". In: VAUBAN (Sébastien le Prestre de). La Dîme royale. (Paris), Imprimerie Nationale, p.10-48.

LADURIE, Emmanuel Le Roy (1994). O estado monárquico. S. Paulo: Cia. das Letras.

LUÍS XIV (1988). Memorias. Mexico, Fondo de Cultura Económica.

LUNDGREEN, Peter (1986). "Gegensatz und Verschmelzung von alter und neuer Bürokratie im Ancien Régime”. In: Hinrichs, E. (Org.). Absolutismus. Frankfurt/M, Suhrkamp, p.162-179.

LYNCH, John (1989). Bourbon Spain. Oxford/Cambridge (MA), Basil Blackwell, 1989.

MACEDO, Jorge Borges de (1989). A situação económica no tempo de Pombal. 3.ed., Lisboa, Gradiva.

MADARIAGA, Isabel de (2002). Russia in the Age of Catherine the Great. London, Phoenix Press.

MAIER, Hans (1980). Die ältere deutsche Staats- und Verwaltungslehre. 2.ed., München, (C.H.) Beck.

MARAVALL, José Antonio.(1997)- A cultura do barroco. S. Paulo, EDUSP. (1997b). Teoria del

Estado em España en el siglo XVII. Madrid, Centro de Estudios Constitucionales

MATSUMOTO, Naoko (1999). Polizeibegriff im Umbruch. Frankfurt, V.Klostermann.

MAXWELL, Kenneth (1994). "Pombal: The Paradox of Enlightenment and Despotism". In: SCOTT, H. M. (Org.). Enlightened Absolutism. Houndmills/London, Macmillan, p.75-118.

MAXWELL, Kenneth (1995). Pombal, Paradox of the Enlightenment. Cambridge, Cambridge University Press.

MESTRE, Jean-Louis (1985). "Du régime seigneurial au droit administratif”. In: HEYEN, Erk V. (Org.). Wissenschaft und Recht der Verwaltung seit dem Ancien Régime. Frankfurt/M., V.Klostermann, p.29-39.

MESTRE, Jean-Louis (1985). Introduction historique au droit administratif français.

MITTEIS, Heinrich/LIEBERICH, Heinz (1992). Deutsche Rechtsgeschichte. 19.ed., München, C.H.Beck.

MOHL, Robert von (2005). Die Polizei-Wissenschaft nach den Grundsätzen des Rechtsstaates. S.l., Elibron/Adamant (reimpressão da 3.ed.Tübingen 1866).

MOHNHAUPT, Heinz (2000e). "Potestas legislatoria und Gesetzesbegriff im Ancien Régime". In: MOHNHAUPT, H. - Historische Vergleichung im Bereich von Staat und Recht. Frankfurt/M, V. Klostermann, p.221-273.

MONTESQUIEU, Charles-Louis de Secondat, Barão de (1973). Do espirito das leis. S. Paulo, Abril. MONTESQUIEU, Charles-Louis de Secondat, Barão de (1990a). "De L'Esprit des Lois". Oeuvres complètes. Paris, Éditions du Seuil, p.527-808.

OBERT, Marcus (1992). Die naturrechtliche 'politische Metaphysik' des Johann Heinrich Gottlob von Justi. Frankfurt a.M./Bern/N.York/Paris, Peter Lang.

OGRIS, Werner (1988). "Aufklärung, Naturrecht und Rechtsreform in der Habsburgermonarchie". in:KRAUSE, Peter (Org.). Aufklärung. V.2 (1988), p.29-52.

OLIVIER-MARTIN, François (1992). Histoire du droit français des origines à la Révolution. Paris, CNRS. 
OLIVIER-MARTIN, François (1997). Les lois du roi. Paris, LGDJ-EJA.

PEREIRA, José Esteves (1983). O pensamento político em Portugal no século XVIII. Lisboa, Imprensa Nacional/Casa da Moeda.

PEREIRA, José Esteves (s.d.). "Genealogia das correntes de pensamento do Antigo Regime ao liberalismo". in:COSTA, F.M. da, DOMINGUES, F.C. e MONTEIRO, N.G. (Org.). Do Antigo Regime ao Liberalismo. Lisboa, Veja, p.47-61.

PÉREZ VALIENTE, Pedro José (2000). Derecho Público Hispánico. Madrid, Centro de Estúdios Políticos y Constitucionales.

PREU, Peter (1983). Polizeibegriff und Staatszwecklehre. Göttingen, Schwartz.

REINHARD, Wolfgang (1986). "Staatsmacht als Kreditproblem”. In: HINRICHS, E. (Org.). Absolutismus. Frankfurt/M., Suhrkamp, p.214-248.

REIS, Paschoal José de Mello Freire dos (1844a). O novo código do direito público de Portugal. Coimbra, Imprensa da Universidade.

REIS, Paschoal José de Mello Freire dos (1844b). "Resposta que deu o desembargador Paschoal José de Mello Freire dos Reis às censuras”. In: REIS, Paschoal José de Mello Freire dos. O novo código do direito público de Portugal. Coimbra, Imprensa da Universidade.

REIS, Paschoal José de Mello Freire dos (1844c). "Resposta à segunda censura". In: REIS, Paschoal José de Mello Freire dos. O novo código do direito público de Portugal. Coimbra, Imprensa da Universidade.

REIS, Paschoal José de Mello Freire dos (1859). Institutiones Juris Civilis Lusitani. Coimbra, Imprensa da Universidade, v.1 (De Jure Publico).

REIS, Paschoal José de Mello Freire dos (1966). "Instituições de direito civil português". Boletim do Ministério da Justiça. 161 (dez.1966): p.89-200.

REIS, Paschoal José de Mello Freire dos (1967a). "Instituições de direito civil português". Boletim do Ministério da Justiça 162 (jan.1967): p.31-139.

REIS, Paschoal José de Mello Freire dos (1967b). "Instituições de direito civil português". Boletim do Ministério da Justiça 163 (fev.1967): p.5-126.

REIS, Paschoal José de Mello Freire dos (1967c). "Instituições de direito civil português". Boletim do Ministério da Justiça 164 (mar.1967): p.17-147.

RIBEYRO, João Pinto (1729a). "Lustre ao Dezembargo do Paço". Obras varias. Coimbra.

RIBEYRO, João Pinto (1729b). “A primeyra relaçam”. Obras varias. Coimbra.

RIBEYRO, João Pinto (1729c). “A segunda relaçam”. Obras varias. Coimbra.

"RICHELIEU" (texto visto como apócrifo) (1996). Testamento politico. S.Paulo, Edipro.

ROBERTS, Michael (1986). "Die militärische Revolution 1560-1660”. In: HINRICHS, Ernst

(Org.). Absolutismus. Frankfurt a.M., Suhrkamp, p.273-309.

RODRIGUES, Manuel Augusto (1989). "O ambiente cultural de Coimbra e a actuação da Inquisição". In: SANTOS, Maria H. Carvalho dos (Org.). Inquisição. Universitária/Soc. Portuguesa de Estudos do Século XVIII, v.1, p.293-302.

SAAVEDRA FAJARDO, Diego de (1988). Empresas políticas. Barcelona, Planeta. 
SALAZAR, Fray Juan de (1997). Política Española. Madrid, Centro de Estudios Políticos y Constitucionales.

SÁNCHEZ AGESTA, Luis (1979). El pensamiento político del despotismo ilustrado. Sevilla, Universidad de Sevilla.

S. PAIO, Francisco Coelho de S. e (1793). Prelecções de direito patrio publico, e particular. Coimbra, Real Imprensa da Universidade.

S. PAIO, Francisco Coelho de S. e (1794). Prelecções de direito patrio particular. Coimbra, Real Imprensa da Universidade.

S. PAIO, Francisco Coelho de S. e (1805). Observações ás prelecções de direito patrio, publico e particular. Lisboa, Imprensa Régia.

SCHIERA, Pierangelo (1986). "Estado de Polícia". In: BOBBIO, N./MATTEUCCI, N./PASQUINO, G. Dicionário de política. Brasília, UNB, p.409-413.

SCHULZE, Reiner (1982). Policey und Gesetzgebungslehre im 18.Jahrhundert. Berlin, Duncker \& Humblot.

SCOTT, H.M. (1994). "The Problem of Enlightened Absolutism”. In: SCOTT, H.M. (Org.).

Enlightened Absolutism. Houndmills, MacMillan, p.1-35.

SEELAENDER, Airton Cerqueira-Leite (1995). Der Gesetzgeber in "Natur und Wesen der Staaten".

Diss. inédita, Faculdade de Direito da J.W. Goethe-Universität (Frankfurt), 1995.

SEELAENDER, Airton Cerqueira-Leite (2003a). Polizei, Ökonomie und Gesetzgebungslehre.

Frankfurt/M., V. Klostermann.

SEELAENDER, Airton Cerqueira-Leite (2003b). “A polícia e o rei-legislador”. in:BITTAR, E.-

História do direito brasileiro. S. Paulo, Atlas, p.91-108.

SEELAENDER, Airton Cerqueira-Leite (2007). "O contexto do texto- notas introdutórias à história do direito público na Idade Moderna”. Seqüência 55 (2007): p.253-286.

SIMON, Thomas (1994). "Recht und Ordnung in der frühen Neuzeit". Rechtshistorisches Journal 13 (1994), p.372-392.

SIMON, Thomas (1995). Politik und "Ius publicum". Blätter für deutsche Landesgeschichte 131 (1995), p.145-169.

SIMON, Thomas (2004). Gute Policey- Ordnungsleitbilder und Zielvorstellungen politischen Handelns in der Frühen Neuzeit. Frankfurt/M., V. Klostermann.

SOLNON, J.-F. (Org.) (1994). Sources d'histoire de la France Moderne. Paris, Larousse.

STOLLEIS, Michael (1983). Pecunia Nervus Rerum. Zur Staatsfinanzierung in der Frühen Neuzeit. Frankfurt/M., V. Klostermann.

STOLLEIS, Michael (1988). Geschichte des öffentlichen Rechts in Deutschland. München, Beck, v.1.

STOLLEIS, Michael (1990a). "Grundzüge der Beamtenethik (1550-1650)". Staat und Staatsräson in der frühen Neuzeit. Frankfurt/M., Suhrkamp, p.197-231.

STOLLEIS, Michael (1990b). "Condere leges et interpretari”. Staat und Staatsräson in der frühen Neuzeit. Frankfurt/M., Suhrkamp, p.167-196.

STOLLEIS, Michael (1990c). "Glaubenspaltung und öffentliches Recht in Deutschland". Staat und Staatsräson in der frühen Neuzeit. Frankfurt/M., Suhrkamp, p.268-297. 
STOLLEIS, Michael (1990d). “Friedrich Meineckes 'Die Idee der Staatsräson' und die neuere Forschung”. Staat und Staatsräson in der frühen Neuzeit. Frankfurt/M., Suhrkamp, p.134-164.

STOLLEIS, Michael (Org.) (1995). Staatsdenker in der frühen Neuzeit. München, C.H. Beck.

SUEUR, Philippe (1993/1994). Histoire du droit public français. 2.ed., Paris, PUF, 1993 (t.1) e 1994 (t.2).

THOMANN, Marcel (1995). “Christian Wolff”. In: STOLLEIS, M. (Org.). Staatsdenker in der frühen Neuzeit. München, CH Beck, p.257-283.

TOCQUEVILLE, Alexis de (1986). “L’Ancien Régime et la Révolution”. In: De la démocratie en Amérique. Souvenirs. L'Ancien Régime et la Révolution. Paris, R. Laffont, p.895-1160.

TOMÁS Y VALIENTE, Francisco (1996). Manual de Historia del Derecho Español. Madrid, Tecnos.

TORGAL, Luís Reis (1981/1982). Ideologia política e teoria do estado na Restauração. Coimbra, Biblioteca Geral da Universidade, 1981 (t.1) e 1982 (t.2).

UNIVERSIDADE DE COIMBRA (1972). Estatutos da Universidade de Coimbra (1772). Coimbra, Universidade de Coimbra, v.2.

VAUBAN, (Sébastien le Prestre de) (1992). La Dîme royale. Paris, Imprimerie Nationale.

VENTURI, Franco (2003). Utopia e reforma no iluminismo. Bauru, EDUSC.

VERNEY, Luís António (1952/1953). Verdadeiro método de estudar. Lisboa, Sá da Costa, v.4 (1952) e 5 (1953).

VIERHAUS, Rudolf (1984). Deutschland im Zeitalter des Absolutismus. 2.ed. rev., Göttingen, Vandenhoeck \& Ruprecht.

VOGLER, Günter (1996). Absolutistische Herrschaft und ständische Gesellschaft. Stuttgart, UTB.

WEHLER, Hans-Ulrich (1989). Deutsche Gesellschaftsgeschichte- 1700-1815. 2. ed., München, C.H. Beck, v.1.

WIEACKER, Franz (1980). História do direito privado moderno. Lisboa, C. Gulbenkian.

WILLIAMS, E.N. (1988). The Ancien Régime in Europe. London, Penguin.

WOLOCH, Isser (1995). The New Regime. N. York/London, W.W. Norton. 